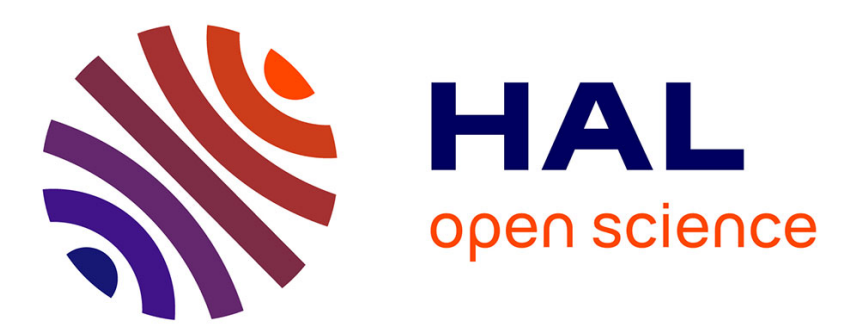

\title{
PMN-PT Piezoelectric material and related applications in silicon-integrated devices like microactuators and energy harvesters.
}

Ioan Alexandru Ivan, Joël Agnus, Micky Rakotondrabe, Philippe Lutz, Nicolas Chaillet

\section{To cite this version:}

Ioan Alexandru Ivan, Joël Agnus, Micky Rakotondrabe, Philippe Lutz, Nicolas Chaillet. PMN-PT Piezoelectric material and related applications in silicon-integrated devices like microactuators and energy harvesters.. IEEE International Semiconductor Conference, CAS'11., Oct 2011, Sinaia, Romania. pp.149-152. hal-00635613

\section{HAL Id: hal-00635613 \\ https://hal.science/hal-00635613}

Submitted on 25 Oct 2011

HAL is a multi-disciplinary open access archive for the deposit and dissemination of scientific research documents, whether they are published or not. The documents may come from teaching and research institutions in France or abroad, or from public or private research centers.
L'archive ouverte pluridisciplinaire $\mathbf{H A L}$, est destinée au dépôt et à la diffusion de documents scientifiques de niveau recherche, publiés ou non, émanant des établissements d'enseignement et de recherche français ou étrangers, des laboratoires publics ou privés. 


\title{
PMN-PT PIEZOELECTRIC MATERIAL AND RELATED APPLICATIONS IN SILICON-INTEGRATED DEVICES LIKE MICROACTUATORS AND ENERGY HARVESTERS
}

\author{
Ioan Alexandru Ivan*, Joël Agnus**, Micky Rakotondrabe**, Philippe Lutz** and \\ Nicolas Chaillet** \\ *Valahia U niversity of Targoviste, Electr. Eng. Fac. B-Dul Unirii 18-20, Targoviste 130082, ROMANIA \\ E-mail: ivan@valahia.ro \\ **FEMTO-ST Institute, AS2M Dpt., 24 Rue Alain Savary, 25000 Besançon, FRANCE \\ E-mail: jagnus@ens2m.fr, \{mrakoton, plutz, nicolas.chaillet\}@femto-st.fr,
}

\begin{abstract}
Most of the actual MEMS (Micro-ElectroMechanical Systems) are Silicon capacitive devices. The reported research provides the means for approaching towards novel concepts combining silicon technology with piezoelectric materials into Piezo-MEMS systems. The presented technology is based on the bonding and patterning of bulk PMN-PT piezoelectric material on a Silicon wafer rather than sputtering thin piezoelectric films (a complementary method generally providing worse piezoelectric propertie)s. On the other hand bulk piezoelectric materials are more suited for micromanipulation actuators or energy harvesters. The advantage of $P M N-P T$ piezoelectric material with respect to the classical PZT ceramics is presented in the context of the latest works. The technology and some results for actuation and energy harvesting are depicted in the paper.
\end{abstract}

Keywords: MEMS, PEZO-MEMS, PIEZOELECTRIC MATERIALS PMN-PT, PZT, MICRO-ACTUATORS, ENERGY HARVESTING.

\section{INTRODUCTION}

During the last decade a noticeable interest can be found in $x \mathrm{~Pb}(\mathrm{Mg} 1 / 3 \mathrm{Nb} 2 / 3) \mathrm{O} 3-(1-$ $\mathrm{x}) \mathrm{PbTiO} 3$ (PMN-PT) [1]. Initially used as a ceramic, then grown into single crystals by modified Bridgman technique or the solid-state single crystal growth, PMN-PT have become commercially available. Those materials exhibit outstanding piezoelectric properties (e.g. $\mathrm{d} 33=3500 \mathrm{pC} / \mathrm{N}, \mathrm{d} 13=-1200 \mathrm{pC} / \mathrm{N}, \mathrm{k} 33=0.95$ etc.) that considerably surpass the PZT ceramics by a factor of 4 to 5 [2].

The current number of reports on PMN-PT increase and diversify, with potential or existing applications in high frequency bulk and surface resonators and filters, sensors and actuators, ultrasonic transducers or energy harvesters. Most applications, which will not be detailed here, apply to the classical mechanical machining (saw dicing, ultrasonic cutting, lapping, polishing etc.) of bulk material while others document very recent MEMS micro-devices, mainly on [3].

The use of high piezoelectric factor monocrystalline materials like PMN-PT which possess better piezoelectric and electromechanical coupling properties than the classical PZT ceramics are thus the first advantage. Another advantage, in fact even more important than the former, is that the proposed solution is compatible with the Silicon micromachining processes. In consequence the miniaturised devices will be able in the future, like an example, to integrate not only the harvesting stage but also to embed a part of analogical electronic circuit.

There are already some very recent reports of using this material for actuators, ultrasonic transducers or energy harvesters, but by using classical structures like stacks and benders. However, we target a notable reduction in sizes and an integration of the active elements into a silicon wafer. For instance such devices containing arrays of flexural beams will allow in the future energy harvesters with significant bandwidth increase.

The paper is organized as follows: Section-2 presents the micromanufacturing technology and provides references to some recent works. Section-3 discusses the material re-polarization and a microactuator design. Section-4 presents comparative results between PMN-PT and PZT as energy harvesters. Section-5 concludes the paper. 


\section{MICROMANUFACTURING}

The technology steps are as follows:

-Lapping and chemically cleaning of the PMNPT wafer.

-Chrome-Gold sputtering on both PMN-PT and Silicon sides - see Fig. 1.b. Gold thickness: >300 nm. Gold layer

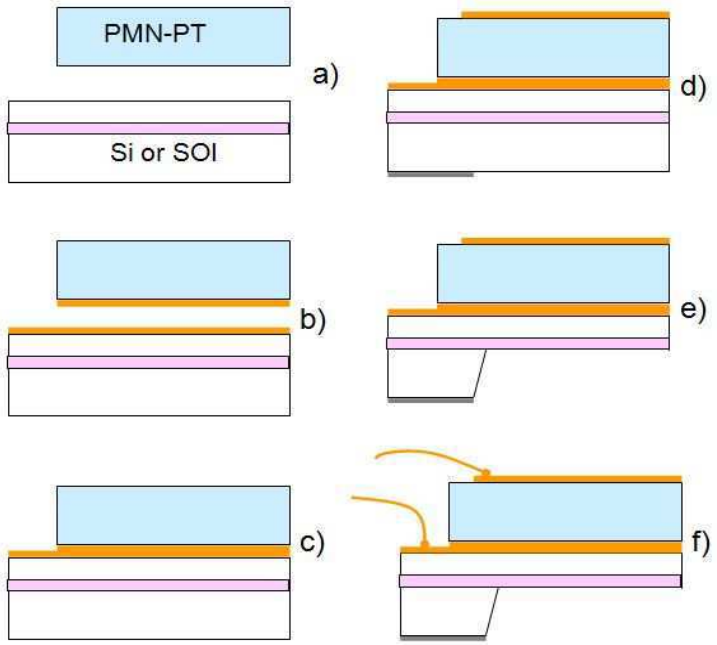

Fig. 1. Microactuator's flowchart: a) initial PMN-PT and Silicon wafers; b) Cr-Au sputtering at interface; c) Gold bonding; d) top electrode ( $\mathrm{Cr}-\mathrm{Au})$ and bottom mask ( $\mathrm{Cr}-\mathrm{Al})$ sputtering; e) saw dicing into individual beams followed by DRIE; f) wire bonding and external poling. As in [4].

-Thermo-compression bonding of the Gold layers; bonding is performed in vacuum, under a pressure of $2 \mathrm{MPa}$ and $60^{\circ} \mathrm{C}$. Bonding time is $\sim 10$ hours. For proper surfaces the bonding quality is insured, as in Fig. 2.

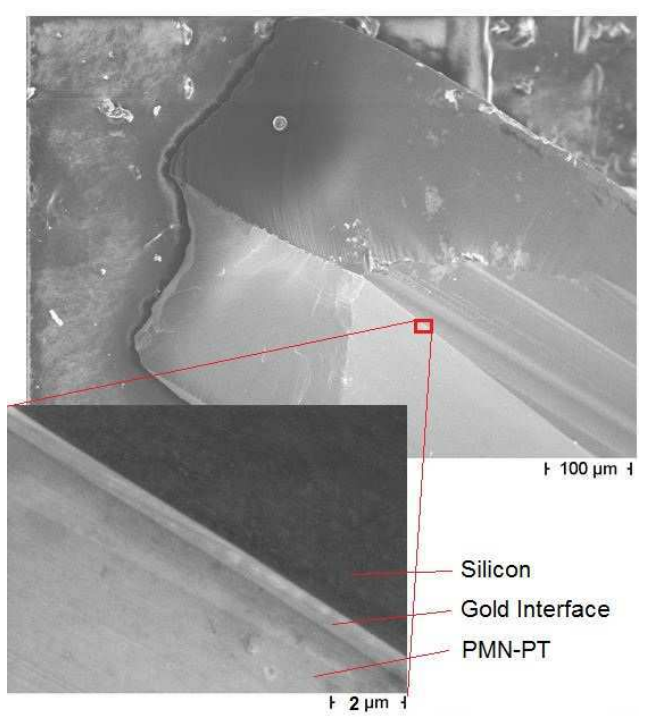

Fig. 2. Scanning electron microscope (SEM) image of a PMN-PT/Si small sample, the fracturing direction shows a very good soldering quality. The middle gold interface $(\sim 0.7$ $\mu \mathrm{m})$ remain intact.

-Chrome-Gold or other metal deposition of the top electrode

-Photolithography of the top electrode followed by wet etch. Lift-off could also be possible.

-Silicon bottom side DRIE-mask construction $\left(\mathrm{SiO}_{2}\right.$, Chrome-Aluminium etc.) (Fig1.d).

-Saw dicing of the wafer into individual beams which will look like in Fig 3. Dicing is performed before DRIE as because of the beams fragility.

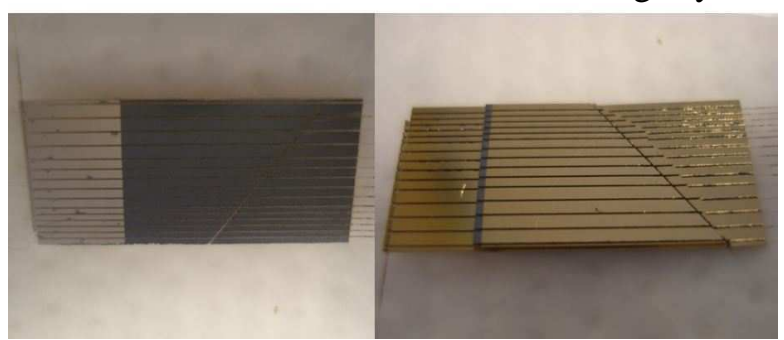

Fig. 3. An array of PMN-PT cantilevers diced and ready for the silicon etching step. Bottom side (left) and top side (right) photos.

-DRIE etching of the bottom silicon side, see Fig 1.e. If the silicon wafer is SOI (silicon-oninsulator) type, there is the advantage of the oxide stopping barer to a fixed thickness. Otherwise, for a bulk Silicon wafer the etching time must be managed to reach the appropriate thickness.

-Conductive paste or gold wire bonding connection as in Fig. 1.f and Fig. 4 right.

-Final external re-poling of the PMN-PT material at room temperature and a constant $10 \mathrm{kV} / \mathrm{cm}$ field for over 10 minutes and testing of the device.

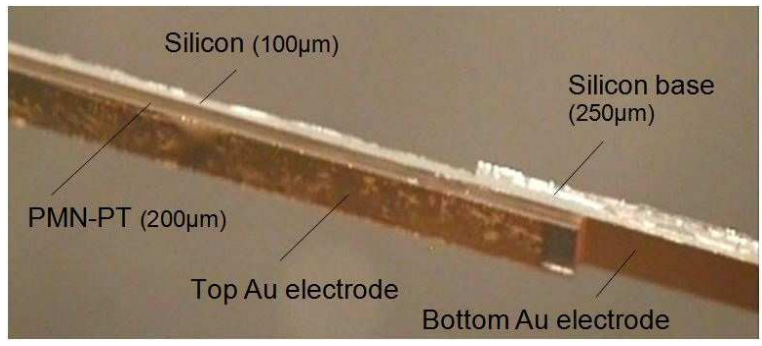

Fig. 4. A PMN-PT on Silicon actuator presented in [4].

As may be seen in Fig. 4, we successfully built the first micromachined PMN-PT on Silicon actuator [4] using the aforementioned technology. Some testing results will be presented in Section 3.

A series of separate tests were performed in the attempt to investigate if etching of PMN-PT is 
feasible. Patterning the PMN-PT material will allow novel and complex devices. Some very recent tests referenced in [5] and [6] detail the reactive ion etching (RIE) of PMN-PT using an Argon-based gas combination and the laser ablation using ArF excimer ultraviolet light.
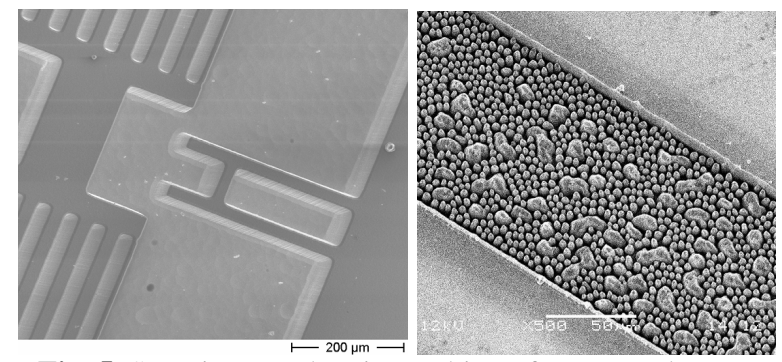

Fig. 5. SEM images showing etching of PMN-PT by RIE technique (left) and by excimer laser ablation (right). The test were performed at FEMTO-ST in France and at Technifutur Liège in Belgium. Further details in [5] and [6].

\section{PIEZOMEMS ACTUATORS}

\section{PMN-PT Material Re-Poling}

The material has to be re-poled due to the high pressure withstood during bonding and due to high temperature during DRIE. The curves were recorded in a low frequency high voltage sine waveform (+/- $200 \mathrm{~V}, 3 \mathrm{mHz}$ or $700 \mathrm{~s})$. Re-poling of the PMN-PT material in both positive and negative field is reversible. Figure 6 show the typical polarization shape. The first conclusion is that the piezoelectric strain vs. the external field (aka the "butterfly" curves) is not symmetrical, for reasons that have to be further investigated. The net stroke is higher in the original positive polarization.

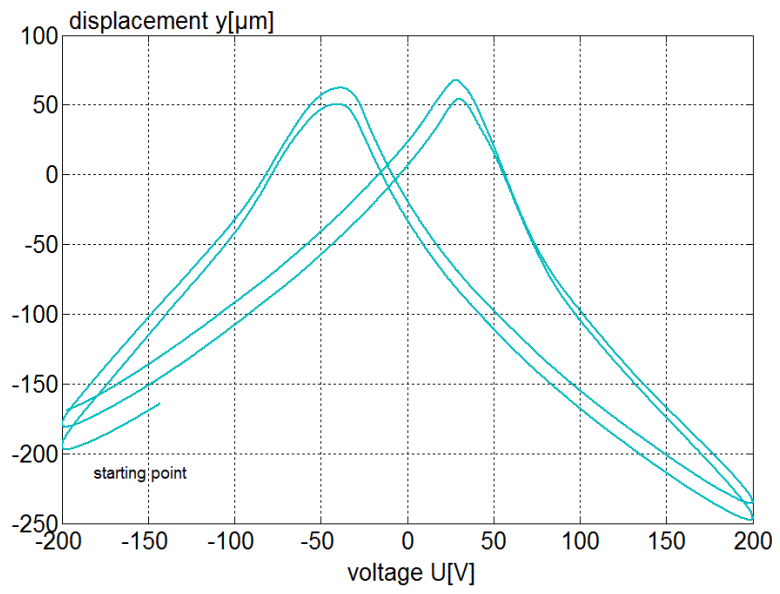

Fig. 6. External re-poling curve of a PMN-PT/Si actuator ( $\mathrm{hSi}=100 \mu \mathrm{m}, \mathrm{hPMN}-\mathrm{PT}=200 \mu \mathrm{m}, \mathrm{w}=0.7 \mathrm{~mm}, \mathrm{~L}=9.3 \mathrm{~mm}$ ). Re_poling cycling frequency is set $0.003 \mathrm{~Hz}$ [4].
The coercitive field of the PMN-PT is quite low compared to PZT, f $-43 \mathrm{~V}$ or $2.15 \mathrm{kV} / \mathrm{cm}$ which prevents large negative signal operation as in the case of PZT.

\section{Actuation and hysteresis properties}

The experimental results four types of PMNPT / Si actuators as well as the PZT / Ni used as a comparison were confronted with the simulation results. There is certain dispersion in the values between different beams, at large and small voltages, either positive or negative The actuation capabilities results are compared to the ones of a classical PZT-ceramic actuator of equivalent size, demonstrating a 3 to 5 times net gain in terms of displacement range at low voltage and 2 to 3 times at high voltage. The dynamics are improved by a factor of $2.5 \mathrm{X}$ for the same actuating range.

Piezoelectric materials typify the hysteresis and creep nonlinearities. The influence of these phenomena generally increased with the amplitude of the applied electric field. In this part, we characterize the small and large signal hysteresis of the developed PMN-PT/Si piezocantilevers.

First, the small signal hysteresis of two PMNPT cantilevers (belonging to the two lots) are compared with the PZT/Ni beam. By small signal we mean voltages that provide symmetric shapes, like up to $40 \mathrm{~V}$. For that, a sine input $\mathrm{U}$ is applied of fixed amplitude and varying frequency, then the output $y$ is reported and finally the curve $(\mathrm{U}, \mathrm{y})$ is plotted for each. As we can see in the Fig. 7 the PMN-PT/Si performs a large stroke with an associated hysteresis larger than to the compared PZT beam.

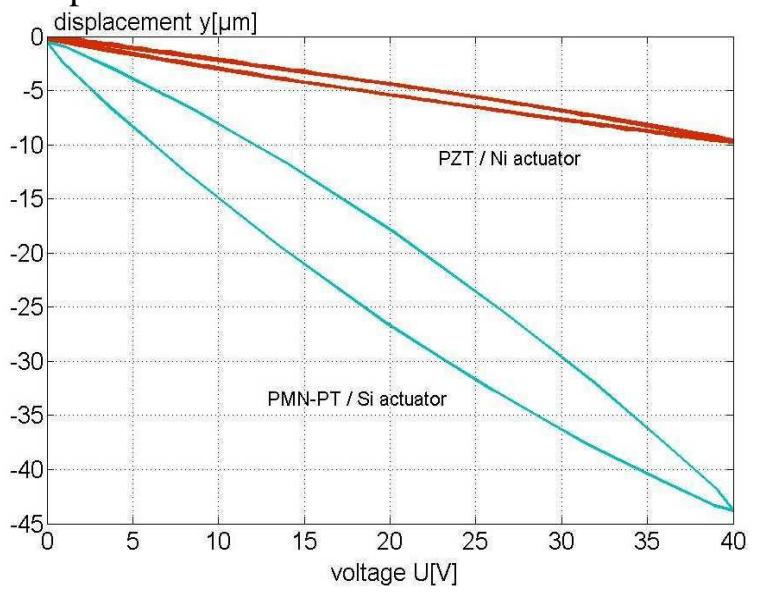

Fig. 7. $0 \mathrm{~V}$ to $40 \mathrm{~V}$ comparative actuator hysteresis characteristics of PMN-PT on silicon and of PZT on Ni. Sizes are $9.3 \mathrm{~mm}$ long, $0.5 \mathrm{~mm}$ wide and $0.3 \mathrm{~mm}$ thick. The PMN-PT provides $4.5 \mathrm{X}$ the actuating range of the PZT. 
The next experiment consisted in applying some large voltage signals $(-40 \mathrm{~V}$ to $200 \mathrm{~V})$ of low frequency $(0.1 \mathrm{~Hz})$, the results being pictured in Fig. 8. In the case of PZT we notice an increased actuation with the voltage but with the cost of a much higher hysteresis. The PMN-PT hysteresis is significantly lower for large positive values but nonlinear; from $50 \mathrm{~V}$ we notice how the saturation starts occurring. As for the reverse fields, hysteresis shape is very large and asymmetric (Fig. 8 left) The PMN-PT material may be driven theoretically until $400 \mathrm{~V}$ but with the cost of an even increased nonlinear behavior.

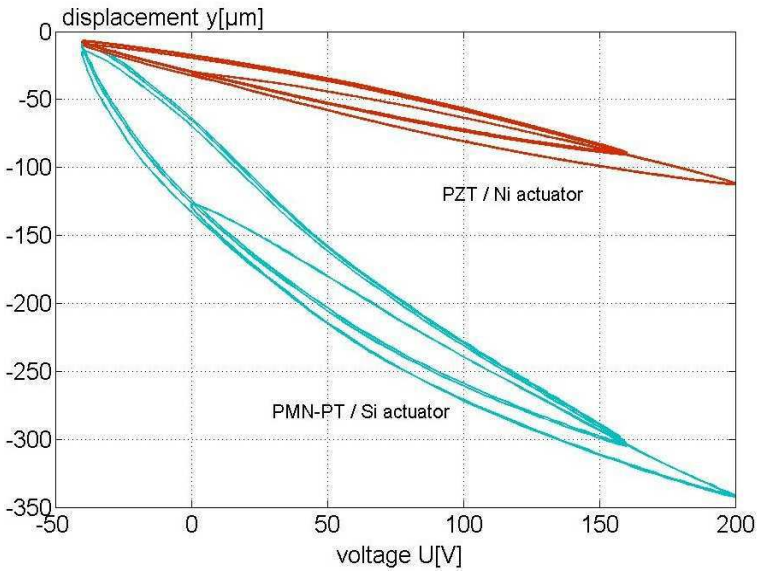

Fig. 8. $-40 \mathrm{~V}$ to $+200 \mathrm{~V}$ large voltage hysteretical behaviour of PMN-PT on silicon and of PZT on Ni. Sizes are: $9.3 \mathrm{~mm}$ long, $0.5 \mathrm{~mm}$ wide and $0.3 \mathrm{~mm}$ thick. The PMN-PT actuator provides $3 \mathrm{X}$ more actuating range than the PZT one.

\section{ENERGY HARVESTERS}

The PMN-PT and PZT materials were also tested as energy harvesters. Two identical cantilevers $17 \mathrm{~mm}$ long (active areas) and $1 \mathrm{~mm}$ wide were submitted to out of plane vibrations by means of a shaker. Vibration levels were imposed to $\pm 0.5 \mathrm{~g}$ amplitude.

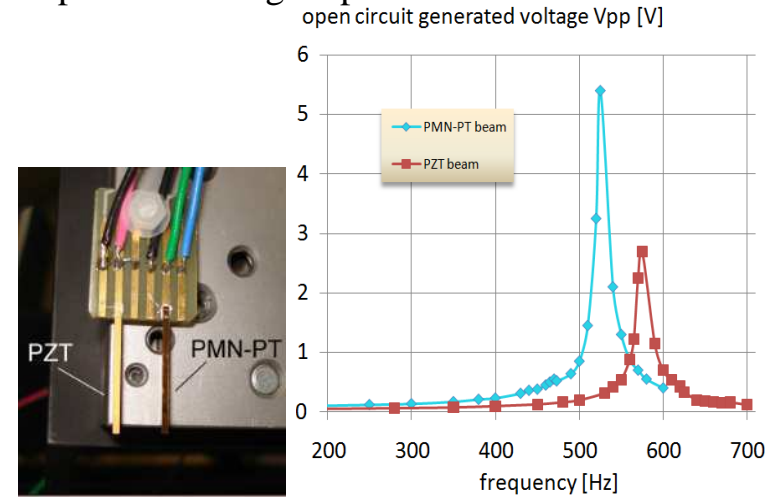

Fig. 9. Comparative PZT and PMN-PT energy harvesting. The open circuit voltage corresponding to $1 \mathrm{~g}$ peak-to-peak acceleration amplitude. The beams are $17 \mathrm{~mm}$ long.
The comparative results from Fig. 9 show a net improvement in terms of open circuit voltage generated by PMN-PT, by a factor of 2 . This fact is particularly important for devices intended to scavenge low amounts of ambient vibration.

These preliminary results were obtained in unoptimised designs; monolithical proof masses will be foreseen to decrease the operating frequency down to several dozen $\mathrm{Hz}$, in the exploitable ambient vibrations range.

\section{CONCLUSIONS}

The overall objectives of the reported works consisted in advancing the research frontier towards more integrated and more autonomous piezoelectric devices such as microactuators or energy harvesters. Some prelimiary results were presented showing first successful PiezoMEMS applications based on bulk PMN-PT on silicon substrate. The electro-mechanical characterization clearly shown a net performance improvement with respect to the classical designs based on PZT ceramics.

Acknowledgements - European Project FP7PEOPLE-ERG 276991/201 - MICROGENS

\section{References}

[1] F. Wang et al., "Complete set of elastic, dielectric and piezoelectric constants of orthorhombic $0.71 \mathrm{~Pb}(\mathrm{Mg} 1 / 3 \mathrm{Nb} 2 / 3) \mathrm{O} 3-0.29 \mathrm{PbTiO} 3 \quad$ single crystal", Appl. Phys. Lett. 90, 212903, 2007

[2] I. A. Ivan et al., "Comparative material study between PZT ceramic and newer crystalline PMNPT and PZN-PT materials for composite bimorph actuators", Rev. Adv. Mat. Sci. (RAMS), No.1/2, Vol.24, pp.1-9, 2010 .

[3] S. Tadigadapa and K. Mateti, "Piezoelectric MEMS sensors: state-of-the-art and perspectives", Meas. Sci. Technol. 20092001 (30pp), 2009.

[4] I. A. Ivan et al., "Microfabricated PMN-PT on Silicon cantilevers with improved static and dynamic piezoelectric actuation: development, characterization and control", IEEE/ASME AIM Proc., Hungary, 2011 J. Agnus et al., "Dry etching of single crystal PMNPT piezoelectric material", IEEE MEMS Conf. Proc., pp. 237-240, Mexico, 2011

[6] I. A. Ivan et al., "PMN-PT piezoelectric material micromachining by excimer laser ablation and dry etching (DRIE)", Sensors and Actuators A: Physical, (under reviewing), 2011 